\title{
Industry reneges on postmarketing trial commitments
}

Recent numbers released by the US Food and Drug Administration (FDA; Rockville, MD, USA) show that industry has dragged its feet in commencing phase 4 postmarketing studies and confirmatory trials-a trend that the agency wants to change. In future, the FDA is likely to favor accelerated approvals only for companies that have confirmatory trials in place, a strategy recently successfully adopted by Millennium Pharmaceuticals (Cambridge, MA, USA) with Velcade, the first in a new class of cancer agents known as proteasome inhibitors, approved by the FDA on May 13 for relapsed and refractory multiple myeloma.

In 1993, the FDA instituted regulations whereby it can grant accelerated approval to drugs that significantly improve treatment outcomes for patients suffering from life-threatening illnesses, in order to get such drugs to market more quickly. Such approvals are based on data from trials that use a surrogate endpoint that reasonably suggests clinical benefit, rather than conventional clinical endpoints that are needed for full marketing approval (see Box 1). However, the FDA grants accelerated approval only with the provision that the drug's sponsor must complete a post- marketing confirmatory trial that uses conventional endpoints to ensure safety and efficacy.

A study released on May 20 by the FDA reveals that of 1,963 postmarketing studies committed to by industry since 1991 , only $20 \%$ have been completed, and $45 \%$ have yet to begin. Although most of these stud-

The poor compliance of drug companies in honoring their postmarketing commitments is a signal that the FDA lacks appropriate authority to regulate the pharmaceutical and biotechnology industries.

ies are voluntary phase 4 trials undertaken by firms that have already received full approval and seek additional indications or demographic markets, many of the uncompleted trials are for drugs that were given accelerated approval. Indeed, at a meeting in March 2003, the FDA's Oncologic Drugs Advisory Committee (ODAC) expressed

\section{Box 1 FDA, NCl collaborate to identify biomarkers for cancer trials}

In an effort to speed the development of cancer drugs, the FDA has begun a joint program with the US National Cancer Institute ( $\mathrm{NCl}$; Bethesda, MD, USA) in order to get new products to patients more quickly. The FDA and $\mathrm{NCl}$ will set up an Oncology Task Force to oversee the program, and will reportedly swap employees to temporarily work in the other's offices in order to facilitate the sharing of knowledge and resources between the two offices.

Many in the biotechnology industry are pleased with the May 30 announcement, especially the plan "to develop a standard approach for evaluating biomarkers that. .can potentially serve in clinical trials as surrogate endpoints..." Bob Pietrusko, vice president of worldwide regulatory affairs at Millennium Pharmaceuticals (Cambridge, MA, USA), says it is unclear whether the FDA and $\mathrm{NCl}$ will look only at pharmacogenomic data voluntarily submitted by biotech and pharma companies ( Nat. Biotechnol. 21, 590, 2003) or also do some basic research on NCl's and companies' compounds. Either way, Pietrusko says, "These developments are very excellent for industry. They [FDA and $\mathrm{NCl}$ ] are drawing on science and the basic workings of disease and targets from genomics in order to determine how to regulate and develop drugs."

Meanwhile, Pietrusko says that the FDA has also been setting up meetings with the American Society of Clinical Oncology (Alexandria, VA, USA) to determine appropriate genetic markers that would be suitable endpoints for both accelerated and full approvals. The first such meeting will be with ODAC concerning lung cancer, although no date has yet been set.

concern that only 4 of 15 anticancer agents granted accelerated approval by the FDA have complete confirmatory trial data.

The poor compliance of drug companies in honoring their postmarketing commitments is a signal that the FDA lacks appropriate authority to regulate the pharmaceutical and biotechnology industries, says Sidney Wolfe, director of Public Citizen's (Washington, DC, USA) health research group, a nonprofit public interest organization. While the FDA can withdraw products that have been granted accelerated approval but have not completed confirmatory trials, Wolfe says this is an extreme measure and it is "preposterous" that the FDA has no legal action to take against noncompliant firms other than withdrawal. "There is no reason for companies to conduct the postmarketing trials because they cost money and there is no real penalty for noncompliance. The FDA needs an act of Congress to implement civil monetary penalties, but this commissioner [McClellan] has made no efforts to do so," says Wolfe.

Certain industry insiders echo Wolfe's criticisms. Raymond Warrell, CEO of Genta (Berkeley Heights, NJ, USA), says that there is frustration at the FDA's inability to confront drug firms' gross noncompliance with completing-or even starting-postmarketing trials. Warrell anticipates that the FDA will use these data "politically, to club sponsors in line." Indeed, members of ODAC have publicly expressed willingness to withdraw cancer drugs that have been granted accelerated approval if industry continues its current rate of failed compliance.

Recent approvals at the FDA suggest the agency is fed up with industry's noncompliance. The FDA granted Millennium's Velcade accelerated approval based on phase 2 data using tumor shrinkage as a surrogate endpoint. Other cancer therapies, such as Campath and Xeloda, had been given accelerated approvals based on similar data in the past; Millenium's approval, however, hinged on its having already initiated its confirmatory trials using the 'gold standard' endpoint of prolonged patient survival. Warrell says that if a sponsor is trying for accelerated approval, then it will need a postmarketing trial in line. "This is definitely a trend," says Warrell.

Aaron Bouchie, New York, NY, USA 